\title{
Students Tendency Toward Illicit Drug Use: The Role of Perceived Social Support and Family Function in Iran
}

\author{
Omid Massah, ${ }^{1}$ Manuchehr Azkhosh, ${ }^{2}$ Yousof Azami, ${ }^{3}$ Ali Akbar Goodiny, ${ }^{4}$ Younes Doostian,,${ }^{, *}$ and \\ Seyed Hadi Mousavi ${ }^{1}$ \\ ${ }^{1}$ Substance Abuse and Dependence Research Center, University of Social Welfare and Rehabilitation Sciences, Tehran, Iran \\ ${ }^{2}$ Counseling Department, University of Social Welfare and Rehabilitation Sciences, Tehran, Iran \\ ${ }^{3}$ Allameh Tabatabaei University, Tehran, Iran \\ ${ }^{4}$ Department of Counseling, Kharazmi University, Tehran, Iran \\ ${ }^{5}$ Student Research Committee, University of Social Welfare and Rehabilitation Sciences, Tehran, Iran \\ "Corresponding author: Younes Doostian, Student Research Committee, University of Social Welfare and Rehabilitation Sciences, Tehran, Iran. Tel: +98-2122180018, Fax: \\ +98-2122180095, E-mail: dostian2438@gmail.com
}

Received 2016 August 15; Revised 2016 October 06; Accepted 2016 October 30.

\begin{abstract}
Background: It is proven that perceived social support and family function are important in the treatment and prevention of lapse or relapse in drug use disorders, but the role of these factors, especially when added together, are less evaluated in primary prevention of drug dependence.

Objectives: The current study aimed to investigate the relationship between perceived social support and family functioning in the students' tendency toward illicit drug use.

Methods: The study had a cross-sectional design. A total of 156 students of Allameh Tabatabaei University were selected in the 2013 - 2014 academic year in Tehran, Iran, and the required information was obtained from them by three questionnaires: perceived social support, family functioning, and students' tendency toward illicit drug use. Data were analyzed with the Pearson correlation coefficient and multiple regression coefficients, by SPSS version 21.

Results: There was a significant relationship $(\mathrm{P}<0.005)$ between perceived social support and students' tendency toward illicit drug use. The family functioning also had a significant correlation with the tendency of students towards drug misuse $(\mathrm{P}<0.001)$. Based on multiple regression coefficients, perceived social support and its components and family function were strong variables to predict illicit drug use potential $(\mathrm{P}<0.001)$.

Conclusions: Improving social support as well as constructive and positive functioning of the family can reduce students' tendency towards illicit drug use. On the contrary, weak social networks and lack of constructive communication between the individuals and society, as well as stressful family environment are among factors of students' and young people' tendency towards drug misuse.
\end{abstract}

Keywords: Drug Dependence, Drug Use Disorders, Family Functioning, Illicit Drug Use, Iran, Perceived Social Support, Students

\section{Background}

In recent decades, the world has encountered alarming statistics regarding the prevalence of drug misuse in society, especially among young population (1). Drug misuse is mostly reported in 18 to 30 years old age group in Iran (2). Prevalence of illicit drug use in modern societies is so high that even educated people are inflicted. For example, drug misuse in universities in Tehran is reported as follows: $16.3 \%$ among art students, $8.85 \%$ among students of the humanities, $6 \%$ among engineering students, and $1.5 \%$ among medical students $(3,4)$. These statistics emphasize the importance of illicit drug use prevention among students.

According to some studies, breaking relationships with addicted peers is extremely stressful and requires new supportive relationships $(5,6)$. One of these sources of support is social support, which today is considered as one of the most important facilitators of healthy behavior. Social support includes acquiring information, material assistance, planning or health advice, or even emotional support from people whom the person is interested in or considers them worthy such as spouse, relatives and friends (7).

Researchers believe that all social relationships are not considered social support, but the ones that are perceived as available or appropriate sources to fulfill the individual's needs. In other words, perceived social support determines whether the existing social relationships are adequate and appropriate for the person or not. Perceived social support is known as an effective moderating factor in dealing and coping with stressful events of life. Family, friends, classmates and neighbors are among the sources 
of social support (8).

Many studies show that perceived social support is important in treatment and prevention of lapse and relapse. Ellis showed that social support available to consumers influences the path of illicit drug use and relapse after treatment (9). Davis and Jason also concluded that abstinence from drugs has positive relationship with receiving social support. Evidently, client's perception of social support improves psychosocial functioning during the treatment process (10).

Family functioning is associated with finding out how the family members interact and maintain relationships, how decisions are made, and how problems related to family members are solved. These functions are related to areas such as the ability of the family to cope with changes, resolving conflict, solidarity between members, success in enforcing disciplinary patterns, observing the boundaries between people and implementation of provisions and principles of the institution with the aim of protecting the whole family. Studies show that family problems can cause falling behind at school, collapse of social relationships, social isolation and the use of alcohol and drugs (11). In their study, Miller et al. (12) concluded that alcoholdependent individuals and families report more family function disorder than non-alcohol dependent ones.

\section{Objectives}

The need to identify predictors and preventive measures in individuals, especially adolescents and young adults as well as educating protective factors against the drug is felt more than ever. In this regard, the current study aimed to examine the prediction of illicit drug use on the basis of perceived social support variables and the family functioning.

\section{Materials and Methods}

\subsection{Study Design}

The current cross-sectional study was designed to evaluate the role of perceived social support and family function in students' vulnerability to illicit drug use.

\subsection{Study Samples}

Study population included all undergraduate students at Allameh Tabataba'i University of Tehran, Iran, enrolled in academic year of 2013-2014. Samples comprised 150 subjects based on sample size in similar correlation studies (13). Three schools (school of psychology and educational sciences, school of social sciences, and school of literature and foreign languages) were randomly selected by twostaged random sampling method among nine schools of the university. Then, from each school, three disciplines at the undergraduate level were randomly selected and questionnaires were distributed among 156 students. Inclusion criteria included having physical and mental health, and willingness to participate in the research.

\subsection{Study Tools}

Data collection was done using multidimensional scale of perceived social support, family assessment questionnaire, and addiction potential scale of Weed and Butcher.

3.3.1. Multidimensional Scale of Perceived Social Support (MSPSS) Includes 12 Statements to Assess Perceived Social Support From Three Sources: Family, Friends, and Other Important People in Life (Significant Others)

Participants express their answers on a 7-point Likerttype scale from strongly disagree (1) to strongly agree (7). The scale score ranges from 12 to 60 . Alpha $(\alpha)$ coefficient of the whole test was 0.91 and $\alpha$ subscales ranged from 0.90 to 0.95 (14). Regarding the validation of this scale in Iran, the obtained alpha was 0.89 (15). In the present study, the Cronbach's alpha coefficient for total score was 0.87 .

3.3.2. Family Assessment Questionnaire Had 60 Questions to Assess Family Functioning Based on a Model Developed at McMaster

Scoring for negative statements is strongly agree (4), agree (3) disagree (2), and strongly disagree (1). Positive scores were scored conversely. High scores on this scale indicate family inefficiency. Alpha coefficient of subscales in the questionnaire ranged from 0.72 to $0.92(16)$. The Cronbach's alpha coefficient in Iran for entire questionnaire is reported 0.94 (17). In the present study, the Cronbach's alpha for entire family functioning in the questionnaire was 0.91 .

3.3.3. Addiction Potential Scale (APS) Was Devised by Weed and Butcher and Consists of Two Factors, Thirty-Six Statements, and Five Lie Detector Statements

Each question is scored on a continuum from zero (completely disagree) to three (strongly agree)(18). In Iran, the validity of scale is calculated using Cronbach's alpha as 0.90 (19). Reliability in this study was 0.83 using Cronbach's alpha coefficient.

\subsection{Statistical Analysis}

Descriptive statistics including frequency, percentage, means and standard deviation were used to report data. 
Pearson correlation coefficient and multiple regression analysis were performed for data analysis, by SPSS version 21.

\subsection{Ethical Considerations}

In order to observe the ethical considerations, the study details were explained to participants and they were assured of their information confidentiality. Participation in the study was voluntary and written consent was obtained from all participants.

\section{Results}

The age range of participants was 19 - 24 years, with the mean age of $21.26 \pm 1.56$ years. Gender and distribution of students in various fields are listed in Table 1.

In Table 2, the mean and standard deviation of variables, along with the correlation coefficient predictor variables and illicit drug use-susceptibility variable are presented.

Based on the results, there was a significant and negative association in the perceived social support and its components with tendency to illicit drug use. The findings also showed a significant and positive relationship between the family functioning (characterized by dysfunctional family) and illicit drug use potential ( $\mathrm{P}<0.005)$.

In Table 3, results of multiple regression analysis for illicit drug use potential are presented on the basis of perceived social support variables and family functioning.

Predicting illicit drug use potential equation by perceived social support variables and family functioning is as follows:

Illicit drug use potential $=[$ (overall perceived support $)$ $\times-11.054]+[($ family functioning $) \times 12.321]+41.261$.

As shown in Table 3, the results of the regression coefficients suggest a multiple relationship among perceived social support, its components, and family function with illicit drug use potential. In other words, perceived social support and its components (perceived social support from family, social support from friends, social support from significant others) and family function are important variables to predict illicit drug use potential.

\section{Discussion}

As one of the first reports from Western Asia, especially the Persian Gulf region, the current study aimed to investigate the association of perceived social support and family function among students with illicit drug use potential. The results indicated a significant relationship between family functioning and illicit drug use potential, i e, dysfunctional family relationships are the underlying factors for illicit drug use; proper family function acts as a shield and guards the individual against tendency towards illicit drug use. To explain these findings, the main concepts that should be noted in analyzing causes of illicit drug use are institutions and networks of mutual relationships. Family is the most important institution in forming and developing character of its members (20). Although individuals experience many interpersonal relationships during their lives, parent-child relationship takes place from an early age and is necessary for compatibility and long-term success of children. A wealth of research support parent-child relationships and its effect on the behavior of young people, especially high-risk behaviors such as drug use. This finding was consistent with findings of other studies such as those of Tilson et al., Yen, Chen, and Chen, Warren and Stein and Davis and Jason (10, 20-22). Factors such as high parent-child conflict, learning about parents' positive attitude toward drug use, and family functioning can be predictors of drug dependence (22). Also, high quality emotional bonds of parent-child are protective factors against many risky behaviors (21).

The scope and depth of penetration and influence of family variables in terms of their importance are studied from different angles. Typically, these variables affect children's vulnerability to drug use and misuse through socialization processes within the family, following exemplars, imitating parents' behaviors, social reinforcement, internalizing values, household behavior, methods of social control and parental discipline (23).

The association of perceived social support and its dimensions with illicit drug use potential in students was another finding of the current study. In other words, those who received more support from family members, friends and significant others tended to use drugs less. Other studies reported this relationship in line with the findings of the current study. For patients, social support is one of the strongest forces to oppose stressful situations and facilitate bearing difficulties (24). Researchers believe that lack of social support increases the incidence of psychiatric disorders and one of these disorders is drug abuse $(25,26)$.

The main finding of the current study was that illicit drug use potential is predictable with a linear combination of perceived social support and family functioning, i e, people with low perceived social support and do not have a well-functioning family, have higher tendency towards drug misuse. This finding was consistent with the findings of previous similar studies. People with low perceived social support and family dysfunction are more likely to use drugs based on synergy of these two negative factors $(7,27$, 28). Proper family functioning is essential for individual, 
Table 1. Demographic Data of the Study Subjects

\begin{tabular}{|lc}
\hline Independent Variables & Statistical Indicators \\
& Frequency (\%) \\
\hline Gender & \\
\hline Male & $82(52.56)$ \\
\hline Female & $74(47.53)$ \\
\hline Field of study & \\
\hline Clinical psychology & $21(13.46)$ \\
\hline Consultation & $17(10.89)$ \\
\hline Exceptional children & $15(9.61)$ \\
\hline Sociology & $14(8.97)$ \\
\hline Social welfare & $18(11.53)$ \\
\hline Journalism & $17(10.89)$ \\
\hline Persian literature & $20(12.82)$ \\
\hline English language & $18(11.53)$ \\
\hline Arabic literature & $16(10.25)$ \\
\hline
\end{tabular}

Table 2. Mean, Standard Deviation and the Pearson Correlation Coefficients of Predictor Variables With Illicit Drug Use Potential

\begin{tabular}{|c|c|c|c|c|c|c|c|c|}
\hline Variables & $\mathbf{M}$ & SD & $\mathbf{1}$ & 2 & 3 & 4 & 5 & 6 \\
\hline 1. Social support from family & 16.11 & 3.12 & 1 & & & & & \\
\hline 2. Social support from friends & 14.47 & 4.61 & $0.214^{\mathrm{a}}$ & 1 & & & & \\
\hline 3. Social support from significant others & 13.52 & 4.01 & $0.614^{\mathrm{b}}$ & $0.170^{\mathrm{a}}$ & 1 & & & \\
\hline 4. General social support from other important persons & 45.56 & 8.18 & $0.530^{\mathrm{b}}$ & $0.671^{b}$ & $0.621^{\mathrm{b}}$ & 1 & & \\
\hline 6. Illicit drug use potential & 29.18 & 12.01 & $-0.320^{\mathrm{b}}$ & $-0.312^{\mathrm{b}}$ & $-0.173^{\mathrm{a}}$ & $-0.380^{\mathrm{b}}$ & $-0.44^{\mathrm{b}}$ & 1 \\
\hline
\end{tabular}

${ }^{\mathrm{a}} \mathrm{P}<0.001$.

${ }^{\mathrm{b}} \mathrm{P}<0.05$.

Table 3. Multiple Regression Coefficients to Predict Illicit Drug Use on the Basis of Perceived Social Support and Family Function

\begin{tabular}{|c|c|c|c|c|c|}
\hline Predictor Variable & B & Standard Error & Beta & $\mathbf{T}$ & $\mathbf{P}$ \\
\hline Fixed value & 41.261 & 4.621 & - & 13.61 & $<0.001$ \\
\hline Social support from family & -6.087 & 0.627 & -0.0858 & -6.02 & $<0.001$ \\
\hline Social support from friends & -4.062 & 0.613 & -0.0510 & -5.31 & $<0.001$ \\
\hline Social support from significant others & -3.641 & 0.514 & -0.480 & -4.51 & $<0.001$ \\
\hline Total perceived social support & -11.054 & 0.675 & -0.679 & -7.11 & $<0.001$ \\
\hline Family functioning & 12.321 & 0.475 & 0.051 & 7.32 & $<0.001$ \\
\hline
\end{tabular}

family and community health. On the other hand, social support in its various forms (family, friends, and significant others) is among protective factors against risky behaviors such as drug use. Previous studies also considered deficiencies in the support (from family and community), the main predictor of behavioral problems in adulthood; therefore, the more perceived social support from family and significant others, the less likelihood of high-risk behavior, including drug use (29).

Due to the student sample recruited in the current 
study, generalizing the results of the study to other noncollege-educated populations is limited. Conducting similar studies in other groups to generalize the results seems to be necessary. Furthermore, it is likely that other variables such as family income level, socioeconomic class, occupation and education level of parents are influential in student tendency towards illicit drug use, which were not investigated in the current study.

\subsection{Conclusion}

Strengthening social support and improving constructive and positive family functions can reduce students' tendency toward illicit drug use. Conversely, weak social networks and lack of constructive communication between individual and society and existence of stressful family environment are among factors responsible for youth and students' tendency towards drug misuse. Since family and society are the most fundamental underlying basis of pre-illicit drug use stage, preventative measures should be taken in the form of family life education, life skills training, educational practices and proper social interaction, etc. to save the gifted youngsters from drug use. Social interactions of teenagers should be taken into consideration and by creating and strengthening emotional atmosphere in the family, likely inclination of at-risk youth to drug misuse can be prevented.

\section{Acknowledgments}

Authors would like to thank all Allameh Tabataba'i University students who helped to conduct the current study.

\section{Footnotes}

Authors' Contribution: Omid Massah and Manouchehr Azkhosh conceived and designed the study. Younes Doostian and Yousef Azami drafted the manuscript. Ali Goodiny and Hadi Mousavi collected and analyzed the data. All authors contributed to writing, reading, editing and approving the paper.

Declaration of Interest: None declared.

Funding/Support: This study was financially supported by student research committee of University of Social Welfare and Rehabilitation Sciences (proposal No.: 801/4697).

\section{References}

1. UNODC. United Nationsofficeon Drugsand Crime World Drug Report; 2015. Available from: http://www.unodc.org/wdr2015/.
2. Momtazi S, Tarjoman T, Haghdoost AA, Saberi Zafirghand MB, Nikfarjam A, et al. Estimating Population Size of Drug and Alcohol Abusers in Iran 2012 [in Persian]. Modeling in Health Research Center; 2012.

3. Taremian F, Bolhari J, Peyravi H. Prevalence of Drug Abuse between Students of Tehran Universities [in Persian]. Iran J Psychiatr Clin Psychol. 2008;13:335-42.

4. Taremian F, Bolhari J, Peyravi H, Asgari A. Drug use prevalence among students of universities of medical sciences in Tehran [in Persian]. Res on Addict. 2014;7(28):9-21.

5. Stevenson LD. The Influence of Treatment Motivation, Treatment Status and Social Networks on Perceived Social Support of Women with Substance Use or Co-Occurring Disorders. Case Western Reserve University; 2009.

6. Maarefvand M, Daneshmand R, Shariatirad S, Massah O, Noroozi A, Hashemian SS. Social Work Guidelines for Street Children with Substance use disorders. Iran Rehabil J. 2015;13(4):120-6.

7. Lin N, Simeone RS, Ensel WM, Kuo W. Social support, stressful life events, and illness: a model and an empirical test.J Health Soc Behav. 1979;20(2):108-19. doi: 10.2307/2136433. [PubMed: 479524].

8. Streeter CL, Franklin C. Defining and measuring social support: Guidelines for social work practitioners. Research on Social Work Practice. 1992;2(1):81-98. doi: 10.1177/104973159200200107.

9. Ellis B, Bernichon T, Yu P, Roberts T, Herrell JM. Effect of social support on substance abuse relapse in a residential treatment setting for women. Evaluation and Program Planning. 2004;27(2):213-21. doi: 10.1016/j.evalprogplan.2004.01.011.

10. Davis MI, Jason LA. Sex differences in social support and self-efficacy within a recovery community. Am J Community Psychol. 2005;36(34):259-74. doi: 10.1007/s10464-005-8625-z. [PubMed: 16389499].

11. Walker R, Shepherd C, Clearinghouse AFR. Strengthening Aboriginal family functioning: What works and why?. Australia: Australian Institute of Family Studies; 2008.

12. Miller IW, Ryan CE, Keitner GI, Bishop DS, Epstein NB. The McMaster approach to families: Theory, assessment, treatment and research.J Family Ther. 2000;22(2):168-89. doi: 10.1111/1467-6427.00145.

13. Massah O, HoseinSabet F, Doostian Y, A'zami Y, Farhoudian A. The Role of Sensation-Seeking and Coping Strategies in Predicting Addiction Potential among Students. Practice in Clin Psychol. 2014;2(3):200-6.

14. Zimet GD, Dahlem NW, Zimet SG, Farley GK. The multidimensional scale of perceived social support. J Person Assessment. 1988;52(1):3041. doi: 10.1207/s15327752jpa5201_2.

15. Joshanloo M, Rostami R, Nosratabadi M. Gender Difference in Determinants of Social Welfare [in Persian]. Psychol Sci. 2006;5(3):184-90.

16. Epstein NB, Baldwin LM, Bishop DS. The McMaster family assessment device. J Marital Family Ther. 1983;9(2):171-80. doi: 10.1111/j.17520606.1983.tb01497.x.

17. Mohammadizadeh A, Malekkhosravi G. A preliminary study of psychometric properties and validity of family assessment device (FAD) [in Persian]. Family Research. 2006;2(5):69-89.

18. Weed NC, Butcher JN, McKenna T, Ben-Porath YS. New measures for assessing alcohol and drug abuse with the MMPI-2: The APS and AAS. J Pers Assess. 1992;58(2):389-404. doi: 10.1207/s15327752jpa5802_15. [PubMed: 1315859].

19. Zargar A, Najarian B, Naami A. The Relationship between Personality Traits (Sensation Seeking, Assertiveness, Psychological Hardiness), Religion Attitudes and Marital Satisfaction with Readiness for Drug Abuse [in Persian]. J Studies Edu Psychol. 2008;1(3):99-120.

20. Yen JY, Yen CF, Chen CC, Chen SH, Ko CH. Family factors of internet addiction and substance use experience in Taiwanese adolescents. Cyberpsychol Behav. 2007;10(3):323-9. doi: 10.1089/cpb.2006.9948. [PubMed: 17594255].

21. Tilson EC, McBride CM, Lipkus IM, Catalano RF. Testing the interaction between parent-child relationship factors and parent smoking to predict youth smoking. J Adolesc Health. 2004;35(3):182-9. doi: 10.1016/j.jadohealth.2003.09.014. [PubMed:15313499]. 
22. Warren JI, Stein JA, Grella CE. Role of social support and self-efficacy in treatment outcomes among clients with cooccurring disorders. Drug Alcohol Depend. 2007;89(2-3):267-74. doi: 10.1016/j.drugalcdep.2007.01.009. [PubMed:17329040].

23. Brook JS, Brook DW, Gordon AS, Whiteman M, Cohen P. The psychosocial etiology of adolescent drug use: a family interactional approach. Genet Soc Gen Psychol Monogr. 1990;116(2):111-267. [PubMed: 2376323].

24. Dobkin PL, De CM, Paraherakis A, Gill K. The role of functional social support in treatment retention and outcomes among outpatient adult substance abusers. Addiction. 2002;97(3):347-56. doi: 10.1046/j.1360-0443.2002.00083.x. [PubMed: 11964111].

25. Falkin GP, Strauss SM. Social supporters and drug use enablers: a dilemma for women in recovery. Addict Behav. 2003;28(1):141-55. doi: 10.1016/S0306-4603(01)00219-2. [PubMed: 12507533].

26. Wasserman DA, Stewart AL, Delucchi KL. Social support and absti- nence from opiates and cocaine during opioid maintenance treatment. Drug Alcohol Depend. 2001;65(1):65-75. doi: 10.1016/S03768716(01)00151-X. [PubMed: 11714591].

27. Hawkins JD, Catalano RF, Miller JY. Risk and protective factors for alcohol and other drug problems in adolescence and early adulthood: implications for substance abuse prevention. Psychol Bull. 1992;112(1):64105. doi: 10.1037/0033-2909.112.1.64. [PubMed: 1529040].

28. Ratelle CF, Simard K, Guay F. University students' subjective wellbeing: The role of autonomy support from parents, friends, and the romantic partner. J Happiness Studies. 2013;14(3):893-910. doi: 10.1007/s10902-012-9360-4.

29. Newcomb MD, Bentler PM. Impact of adolescent drug use and social support on problems of young adults: a longitudinal study. J Abnorm Psychol. 1988;97(1):64-75. doi: 10.1037/0021-843X.97.1.64. [PubMed: 3351114]. 